LIVER

\title{
Hepatitis $C$ virus among childbearing women in Scotland: prevalence, deprivation, and diagnosis
}

\section{S J Hutchinson, D J Goldberg, M King, S O Cameron, L E Shaw, A Brown, J MacKenzie, K Wilson, L MacDonald}

See end of article for authors' affiliations

.....................

Correspondence to: Ms S J Hutchinson, Scottish Centre for Infection and Environmental Health, Clifton House, Clifton Place, Glasgow G3 7LN, UK; sharon.hutchinson@ scieh.csa.scot.nhs.uk

Accepted for publication 12 November 2003

\begin{abstract}
Objectives: (A) To examine the prevalence and demographic characteristics of hepatitis $\mathrm{C}$ virus (HCV) infection among childbearing women in Scotland; and (B) to determine the extent of maternal HCV infection diagnosed prior to birth.

Methods: (A) Residual dried blood spot samples from routine neonatal screening, collected throughout Scotland during March-October 2000, were unlinked from identifiers and tested anonymously for HCV antibodies; and (B) electronic record linkage of Scotland's databases of births and diagnosed HCV infections was performed.

Results: (A) Of 30259 samples, 121 were enzyme linked immunosorbent assay repeat reactive and 88 of these were confirmed as anti-HCV positive in the recombinant immunoblot assay, representing a seroprevalence of $0.29-0.40 \%$. HCV seroprevalence was high among $25-29$ year olds $(0.4-0.57 \%)$, in high deprivation areas (0.92-1.07\%), and in Greater Glasgow (0.83-0.96\%) and Grampian (0.38$0.62 \%)$. Adjusted relative risk for $\mathrm{HCV}$ infection was highest among residents in high deprivation areas of Glasgow (7.2 (95\% confidence interval 2.0-25.5)). (B) Of $121 \mathrm{HCV}$ infections found among women at delivery, $24 \%$ and $46 \%$ were estimated to have been diagnosed prior to pregnancy and birth, respectively. Conclusions: HCV prevalence among Scottish childbearing women is consistent with that expected from injecting drug use. Based on reported rates of mother to child transmission, 8-11 paediatric infections are expected per annum. Diagnosis in only $24 \%$ of infected women prior to pregnancy indicates the extent to which HCV goes unrecognised in the injecting community. The current HCV screening approach-to test only those with a history of injecting drug use (or other risk factors for infection)-identifies approximately a quarter of previously undetected infections among pregnant women.
\end{abstract}

$\mathrm{H}$ epatitis $\mathrm{C}$ virus (HCV) infection is now recognised as a worldwide public health problem. ${ }^{12}$ In Scotland, and in other developed countries, the principal population group infected and at risk of infection with HCV is that which injects drugs. ${ }^{3}$ Transmission of HCV through blood transfusion, largely, was eliminated by the introduction of anti-HCV screening of blood donors in the early $1990 \mathrm{~s}^{5}$ and, although some studies have implicated "number of sexual partners" and "having an injecting drug user (IDU) sexual partner" ${ }^{\prime 7}$ as risk factors, sexual transmission of $\mathrm{HCV}$ appears to be infrequent. ${ }^{8}$ Accordingly, injecting risk behaviour is considered to be the predominant mode of infection in women of childbearing age.

The rate of HCV transmission from viraemic mothers to their babies is estimated at $6-7 \%$; this rate rises considerably if women are coinfected with human immunodeficiency virus (HIV)..$^{9-11}$. While HCV related morbidity during childhood is infrequent, ${ }^{12}$ the longer term consequences of infection are unknown. ${ }^{13}$

Currently, there is agreement that pregnant women should not be offered and recommended a HCV test ${ }^{14-17}$ because, unlike for HIV and hepatitis B virus (HBV) infections, no effective intervention to reduce the probability of mother to child transmission of HCV exists; ribavirin, one of the key components of combination therapy for those infected with $\mathrm{HCV}$, is contraindicated for use in pregnancy because of its potential teratogenicity and there is as yet some but no compelling evidence that elective caesarean section can reduce transmission. ${ }^{11}$ Local, national, and international guidelines however state that persons who have ever injected drugs should be offered a HCV $\operatorname{test}^{18}{ }^{19}$; as it is clinically appropriate to ask attenders of antenatal clinics if they use drugs and as blood is routinely taken from them to screen for maternal infections (HIV, HBV, syphilis, and rubella), it follows that all pregnant women who declare ever having injected drugs should be offered a HCV test so that those infected, but not their babies, might ultimately benefit from such knowledge.

Many studies to determine the prevalence of HCV among pregnant women have been undertaken but none has covered the pregnant population of an entire country or have incorporated methods to gauge the proportions of the infected population who (i) were diagnosed anti-HCV positive before and during pregnancy and (ii) remained undiagnosed. Furthermore, in an era when resource rich countries are acutely aware of the association between poverty and disease, and actively promote policies to reduce inequity, few studies have examined the possible links between deprivation and HCV infection.

Accordingly, the investigators set out to undertake a survey of HCV prevalence among childbearing women throughout Scotland, a country known to have one of the highest IDU, and HCV among IDU, prevalences in Europe, ${ }^{20}$ to provide an understanding of the distribution of infection geographically and-through the use of area of residence data-by deprivation status. As the pregnant population is largely

Abbreviations: $\mathrm{HCV}$, hepatitis $\mathrm{C}$ virus; IDU, injecting drug user; $\mathrm{HIV}$, human immunodeficiency virus; HBV, hepatitis $B$ virus; ELISA, enzyme linked immunosorbent assay; RIBA, recombinant immunoblot assay; SCIEH, Scottish Centre for Infection and Environmental Health; SMR, Scottish Morbidity Record 
unaffected by cultural, behavioural, and economic biases, the resulting data would inform (i) modelling work to estimate the total number of prevalent HCV infections among adults in Scotland and (ii) the allocation of resources, nationally, regionally, and locally, for implementation of interventions to prevent infection. The investigators also set out to estimate the proportion of infected pregnant women who had been diagnosed before and during their pregnancy. Such information would gauge the effectiveness of the existing de facto selective policy of offering a HCV test to pregnant women who have ever injected drugs in detecting all infected pregnant women.

\section{METHODS \\ Setting}

The study population comprised women who delivered live babies in Scotland between mid March and mid October 2000 (31 107 of a total of 53076 for the full year) $)^{21}$; the exact inclusion dates of the study period could not be deduced because only the quarter year, rather than the date, of delivery was recorded with each woman's study results to retain anonymity. While data on ethnicity and country of birth were not available, the great majority of these women would have been Caucasian and indigenous to Scotland..$^{22}$

\section{Design}

The study can be categorised into the following components: (i) unlinked anonymous HCV testing of blood from neonates; (ii) analysis of HCV prevalence by the mother's age, health board area of residence, and deprivation status; (iii) linkage of records from Scotland's database of diagnosed HCV cases (for women known to be infected) with those from Scotland's maternity inpatient and day case register (for women delivering live births); and (iv) analysis of diagnosed and undiagnosed HCV positive women before and during pregnancy. The first two components involved the whole study group of 31107 women, and the third and fourth components involved a reduced group of 26488 women who had delivered live births during the second and third quarter of the year (that is, between 1 April and 30 September); for the latter, it was necessary to restrict the analysis to an exact time period (to allow an alignment with findings obtained from the record linkage described in (iii) below), and thus 4619 women who had delivered on unspecified days during March and October 2000 were excluded. The four components are described in detail below and analyses described in (ii) and (iv) are presented in the results. Analyses were performed using SPLUS ${ }^{23}$ and StatXact ${ }^{24}$ software.

\section{(i) Unlinked anonymous HCV testing of blood from neonates}

Heel prick blood samples, spotted onto filter paper (Guthrie cards), are routinely taken from all newborns in Scotland and sent to the Scottish Inborn Errors Screening Laboratory at Yorkhill Hospital, Glasgow, UK, for metabolic screening..$^{25}$ The nurse who takes the sample enters information, which includes the mother's date of birth and address, on the Guthrie card. After all routine laboratory tests were completed, non-repeat residual dried blood spot specimens were punched out from the Guthrie cards and irreversibly unlinked from patient identifiers using established methods. ${ }^{25}$ While full identifiers were removed from those residual specimens, certain non-identifying details-mother's age and postcode district of residence-were retained and linked to each specimen, in the form of a code, prior to anonymous testing; data on potential risk factors for acquiring blood borne virus infection were not collected. Information, on posters and leaflets, which indicated that anonymous testing for HIV and other infectious diseases might be performed on leftover blood samples, was made available to the women; mothers expressing an objection to testing of their baby's blood were excluded from the survey. The methods used for this unlinked anonymous testing programme were approved by ethics committees in all of Scotland's 15 health boards. Government approval to allow the programme to incorporate HCV, in addition to HIV, testing was given in 1996.

Previous studies have demonstrated that newborns of HCV infected mothers have detectable HCV antibodies, which they have acquired through passive transplacental transfer and can persist for up to $15-18$ months of age ${ }^{11}{ }^{12}$; the presence of passively acquired maternal antibodies in a newborn was thus an ideal surrogate for the presence of HCV antibodies in the mother. At the metabolic screening laboratory, dried blood spot specimens from newborns were eluted and tested for HCV antibodies using a previously validated, highly sensitive "inhouse" IgG enzyme linked immunosorbent assay (ELISA) which incorporated the recombinant proteins c22-3, C200, and NS5 ${ }^{2627}$; a technique for detecting anti-HCV in dried blood spots using a commercially available assay has since been developed and could readily be used by other groups.$^{28}$ Specimens which were reactive in the primary screening test were sent to the Virus Laboratory, Glasgow, UK, for repeat testing in the same ELISA and for supplemental testing by a modification of the recombinant immunoblot assay (RIBA-3; Chiron Corp., Emeryville, California, USA). Test results for HCV (and HIV) were united with their corresponding epidemiological data and sent to the Scottish Centre for Infection and Environmental Health (SCIEH) for analysis.

(ii) Analysis of HCV prevalence by mother's age, health board area of residence, and deprivation status

Maximum (and minimum) HCV seroprevalence was calculated by dividing the number of samples which were repeat reactive on ELISA (and confirmed positive on supplementary RIBA) by the number of samples tested; exact $95 \%$ confidence intervals (CIs) for the minimum and maximum HCV seroprevalences for the whole study group were also calculated using the Clopper-Pearson method. ${ }^{24}$ Unadjusted and adjusted logistic regression models were used to assess the association between demographic characteristics of women-age band, health board area of residence, and level of deprivation-and maximum HCV seroprevalence; women with missing information on one of the three demographic factors were excluded. All main effects and second order interactions, statistically significant at the 5\% level, were included in the adjusted model. As a sensitivity check, regressions were also performed for minimum HCV seroprevalence and produced comparable findings (data not shown).

The deprivation measure was based on the Carstairs and Morris index, which combines four census indicators (overcrowding, unemployment, social class, and car ownership), judged to represent material disadvantage in the population, into a single composite seven point score, ranging from very affluent (1) to very deprived (7), for each postcode sector in Scotland..$^{29}$ The Carstairs index was recategorised, for the purposes of this study, to provide a crude score of deprivation for each woman based on her postcode district of residence: highest deprivation was assigned to women whose postcode district had greater than $50 \%$ of its population residing in areas rated as Carstairs scale 6-7; lowest deprivation was assigned to women whose postcode district had greater than $50 \%$ of its population residing in areas rated as Carstairs scale 1-2 (see footnote of table 1 for all categories). Linear least squares regression was used to examine the relationship between maximum HCV seroprevalence and extent of high deprivation (measured as the percentage of women's 
Table 1 Prevalence and demographic determinants of hepatitis $\mathrm{C}$ virus $(\mathrm{HCV})$ infection among childbearing women in Scotland during 2000

\begin{tabular}{|c|c|c|c|c|c|c|c|}
\hline & \multirow[b]{3}{*}{ No tested (\%) } & \multirow{2}{*}{\multicolumn{2}{|c|}{$\begin{array}{l}\text { No anti-HCV positive } \\
\text { Repeat reactive on ELISA } \\
\text { and }\end{array}$}} & \multicolumn{2}{|c|}{ Seroprevalence $(\%) \ddagger$} & \multirow{2}{*}{\multicolumn{2}{|c|}{$\begin{array}{l}\text { Relative risk for maximum HCV } \\
\text { seroprevalence }(95 \% \mathrm{CI}) \S\end{array}$}} \\
\hline & & & & \multirow[b]{2}{*}{ Minimum } & \multirow[b]{2}{*}{ Maximum } & & \\
\hline & & $\begin{array}{l}\text { Confirmed } \\
\text { on RIBA }\end{array}$ & $\begin{array}{l}\text { Unconfirmed } \\
\text { on RIBA }\end{array}$ & & & Unadjusted & Adjusted \\
\hline Scotland & $30259(100 \%)$ & 88 & 33 & 0.29 & 0.40 & - & - \\
\hline \multicolumn{8}{|l|}{ Health board area of residence* } \\
\hline Greater Glasgow (GG) & $5188(17 \%)$ & 43 & 7 & 0.83 & 0.96 & $4.17(2.82-6.17)$ & $0.74(0.27-2.06)$ \\
\hline Grampian (GR) & $2913(10 \%)$ & 11 & 7 & 0.38 & 0.62 & $2.72(1.59-4.66)$ & $2.82(1.62-4.89)$ \\
\hline Lothian & $4887(16 \%)$ & 4 & 3 & 0.08 & 0.14 & & \\
\hline Tayside & $2224(7 \%)$ & 3 & 3 & 0.13 & 0.27 & & \\
\hline Rest of: West/Central & $9202(30 \%)$ & 22 & 10 & 0.24 & 0.35 & 1.00 (Baseline) & 1.00 (Baseline) \\
\hline East & 4257 (14\%) & 5 & 3 & 0.12 & 0.19 & & \\
\hline North & $1574(5 \%)$ & 0 & 0 & 0 & 0 & & \\
\hline (Not known) & (14) & (0) & (0) & & & & \\
\hline \multicolumn{8}{|l|}{ Age (y) } \\
\hline$<20$ & $2029(7 \%)$ & 0 & 3 & 0 & 0.15 & 1.00 (Baseline) & 1.00 (Baseline) \\
\hline $20-24$ & $4926(17 \%)$ & 18 & 5 & 0.37 & 0.47 & $3.18(0.96-10.50)$ & 3.38 (1.03-11.13) \\
\hline $25-29$ & $7751(26 \%)$ & 31 & 13 & 0.40 & 0.57 & 3.88 (1.22-12.39) & $4.53(1.42-14.43)$ \\
\hline $30-34$ & $9370(32 \%)$ & 30 & 6 & 0.32 & 0.38 & $2.62(0.81-8.42)$ & $3.35(1.04-10.77)$ \\
\hline$\geqslant 35$ & $5518(19 \%)$ & 7 & 6 & 0.13 & 0.24 & $1.61(0.46-5.61)$ & $2.10(0.60-7.29)$ \\
\hline (Not known) & $(665)$ & (2) & (0) & & & & \\
\hline \multicolumn{8}{|l|}{ Level of deprivation $†$} \\
\hline 1 (low) & $5574(19 \%)$ & 8 & 8 & 0.14 & 0.29 & & \\
\hline 2 & $6064(20 \%)$ & 11 & 4 & 0.18 & 0.25 & 1.00 (Baseline) & 1.00 (Baseline) \\
\hline 3 & $9544(32 \%)$ & 16 & 8 & 0.17 & 0.25 & & \\
\hline 4 & 3701 (12\%) & 6 & 5 & 0.16 & 0.30 & & \\
\hline 5 (high) & $5139(17 \%)$ & 47 & 8 & 0.92 & 1.07 & $4.04(2.82-5.81)$ & $1.49(0.70-3.18)$ \\
\hline (Not known) & (237) & (0) & (0) & & & & \\
\hline \multicolumn{8}{|c|}{ Interaction in adjusted regression model: Health board area of residence and level of deprivation } \\
\hline GG and 5 (high) & $2695(9 \%)$ & 40 & 6 & 1.48 & 1.71 & - & $7.17(2.02-25.46)$ \\
\hline GR and 5 (high) & $0(0 \%)$ & - & - & - & - & - & - \\
\hline \multicolumn{8}{|c|}{ 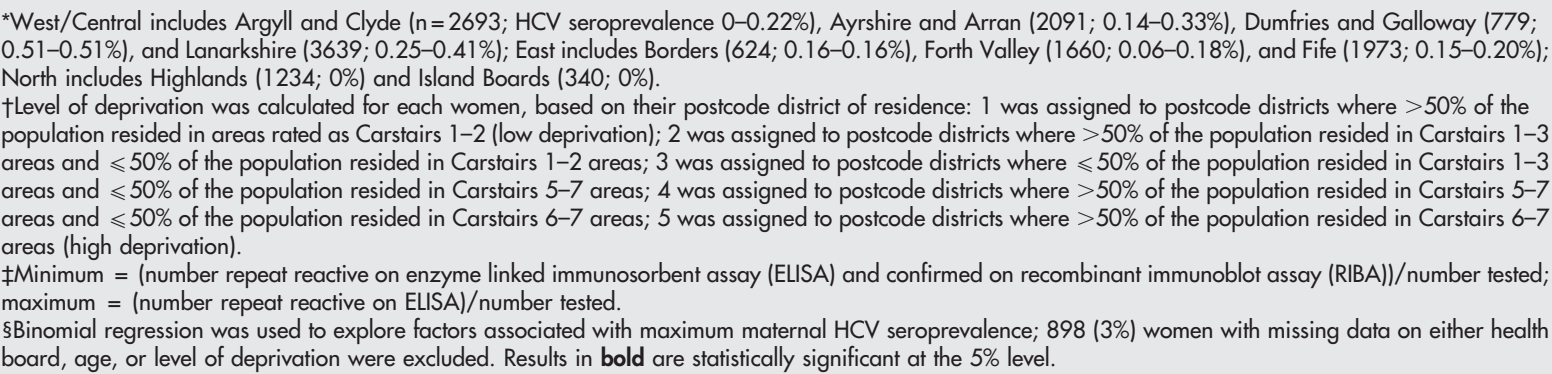 } \\
\hline
\end{tabular}

postcode district of residence rated as Carstairs categories 6 and 7) among women in Greater Glasgow.

\section{(iii) Linkage of records from Scotland's database of diagnosed HCV cases with those from Scotland's maternity inpatient and day case register}

SCIEH holds epidemiological data (including (i) forename initial, (ii) surname initial, (iii) surname soundex, (iv) date of birth, (v) sex, (vi) postcode district of residence, (vii) date of anti-HCV positive test result, and (viii) risk category) on all persons diagnosed anti-HCV positive in Scotland up until December 2001. ${ }^{31}$ To determine the number of mothersdelivering live babies during 1 April to 30 September 2000who had been diagnosed as anti-HCV positive before or during pregnancy, records from SCIEH's HCV diagnosis database were electronically linked to those held on Scotland's maternity inpatient and day case register (Scottish Morbidity Record (SMR) 02) ${ }^{32}$ for the period 1 April to 30 September 2000, by the Information and Statistics Division Record Linkage Team, Edinburgh, UK, using a probability matching approach ${ }^{33}$; the data variables used in the linkage process were (i) to (vi) above (available for $89 \%$ of females on the HCV diagnosis database). The linkage was approved by the Privacy Advisory Committee, which oversees issues of confidentiality involving data on National Health Service patients in Scotland.

\section{(iv) Analysis of diagnosed and undiagnosed HCV} positive women before and during pregnancy

Matches obtained from the linkage, described in (iii) above, on diagnosed anti-HCV positive mothers who had delivered live babies during 1 April to 30 September 2000 were categorised as known infected pre or during pregnancy if the interval between a mother's date of first positive HCV antibody specimen (from the HCV diagnosis database) and date of delivery (from SMR 02) exceeded nine months or was within zero and nine months, respectively. To determine the proportion of anti-HCV positive women delivering a live baby during 1 April to 30 September 2000 who knew of their HCV status either pre or during pregnancy, age and health board area of residence variables from the above matched records were aligned with the corresponding variables from the records of women who were detected as anti-HCV positive through the unlinked anonymous testing survey. Pearson's $\chi^{2}$ test was used to compare antenatal HCV detection rates between age groups of mothers. 


\section{RESULTS}

Analysis of HCV prevalence by mother's age, health board area of residence, and deprivation status

Of the total 31107 Guthrie cards available, 30259 (97\%) were tested for HCV antibodies; 838 were of insufficient volume and 10 were not tested because of parental refusal. The minimum and maximum HCV seroprevalences were $0.29 \%$ ( $95 \%$ CI $0.23-0.36 \%$ ) (that is, repeat reactive on ELISA and confirmed on RIBA) and $0.40 \%$ (95\% CI $0.33-0.48 \%$ ) (that is, repeat reactive on ELISA), respectively. Of the 12 women who were anti-HIV positive ( $0.04 \%$ of the total), none was anti-HCV positive.

In unadjusted logistic regression, maximum HCV seroprevalence differed significantly by region, age, and level of deprivation (table 1). Greater Glasgow and Grampian residents were significantly more likely to be anti-HCV positive (unadjusted relative risks 4.2 and 2.7 (95\% CIs 2.86.2 and 1.6-4.7), respectively) than women who lived elsewhere in Scotland. Maximum HCV seroprevalence peaked among 25-29 year olds for all Scotland (0.57\%) and for residents of Greater Glasgow (1.56\%) but was highest among 20-24 year olds in Grampian (1.59\%). HCV infection also predominated among women residing in areas of high deprivation: $45 \%(55 / 121)$ of all infections in Scotland, increasing to $92 \%(46 / 50)$ in Greater Glasgow (compared with $52 \%(2649 / 5138)$ of anti-HCV negatives; $\chi^{2}(1)=30.8$, $\mathrm{p}<0.0001$ ) were among women residing in postcode districts where greater than half of the population were categorised by Carstairs index 6 and 7. High deprivation however was not significantly associated with HCV infection outside Greater Glasgow (fig 1). Figure 2 shows a strong positive linear relation between maximum HCV seroprevalence and extent of high deprivation (measured as the percentage of women's postcode district of residence rated as Carstairs categories 6 and 7) among women in Greater Glasgow $(\mathrm{p}<0.001)$.

In adjusted logistic regression (table 1), childbearing women who (i) resided in Grampian, (ii) were aged 2034 years, and (iii) both resided in Greater Glasgow and in an area of high deprivation were significantly more likely to be anti-HCV positive (based on repeat reactive ELISA tests);
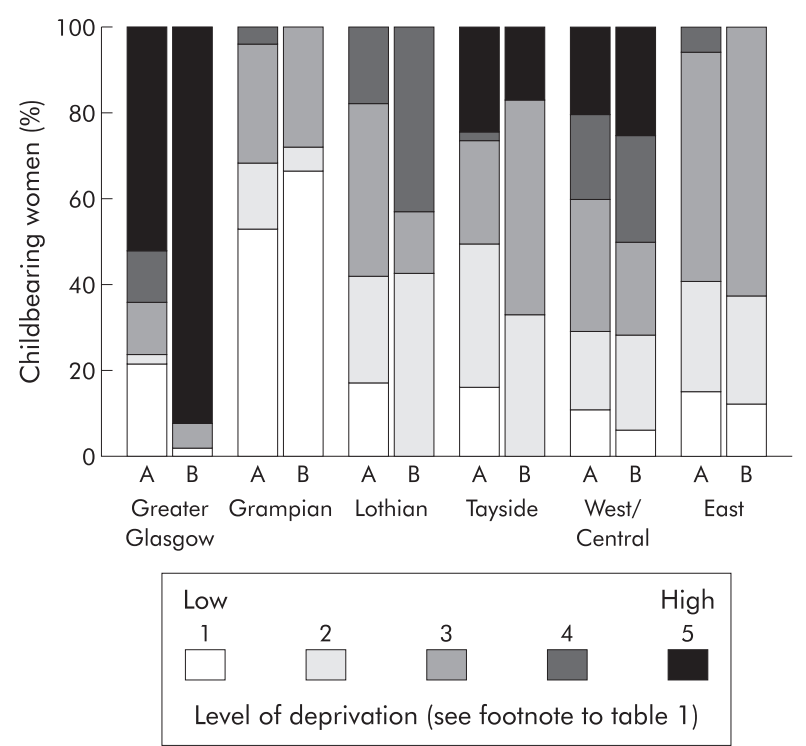

Figure 1 Distribution of deprivation among (A) all childbearing women and (B) anti-hepatitis $C$ virus (HCV) infected (that is, repeat reactive on ELISA) childbearing women by health board region in Scotland, 2000 (North, including Highlands and Islands boards, had no anti-HCV positive cases and are therefore not represented in this display).

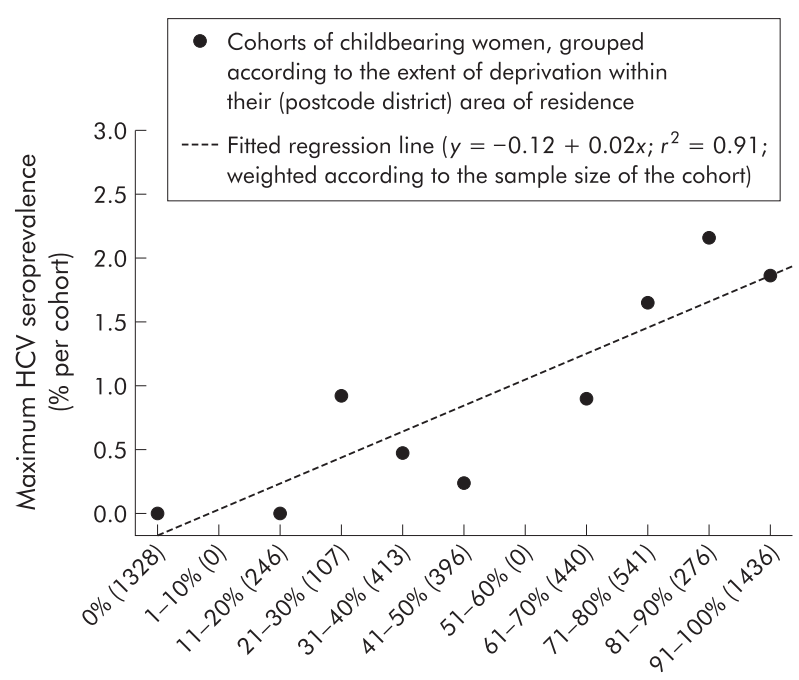

Women assigned according to the percentage of their postcode district population residing in areas rated as Carstairs scale 6 and 7 (sample size of cohort)

Figure 2 Maximum hepatitis $\mathrm{C}$ virus (HCV) seroprevalence among childbearing women, from Greater Glasgow in 2000, according to the extent of deprivation (measured by Carstairs) in the women's postcode district area of residence.

group (iii) had the highest maximum HCV seroprevalence (1.7\%) and adjusted relative risk (7.2 (95\% CI 2.0-25.5)).

\section{Analysis of diagnosed and undiagnosed HCV positive women before and during pregnancy}

Of the $121 \mathrm{HCV}$ infections detected among women at the time of delivery (based on samples which were repeat reactive in ELISA), 112 gave birth during April-September 2001. Age and health board area of residence of these 112 women were aligned with those who had given birth during the same period and were also known to be HCV infected (table 2). An estimated $24 \%$ and $46 \%$ of 112 HCV infected women had been diagnosed prior to pregnancy and birth, respectively; thus $47 \%(24 / 51)$ of all diagnoses occurred during pregnancy. Among the 51 diagnosed cases, 40 had ever injected drugs (95\% of the 42 cases for whom at least one risk factor was known), two reported heterosexual contact, and no information was available for the remaining nine. Hence of the 85 mothers whose HCV infections had not been detected prior to pregnancy, 24 (28\%) were estimated to have been diagnosed during the antenatal period. The antenatal HCV detection rate among women aged $<25$ years (72\%; 13/18) was significantly higher than for those aged $\geqslant 25$ years $(17 \% ; 11 / 65)\left(\chi^{2}=18.4 ; \mathrm{p}<0.0001\right)$.

\section{DISCUSSION}

The worldwide literature on HCV prevalence has increased considerably over the past decade yet few surveys have been conducted at a national level. ${ }^{34}$ Hitherto, maternal HCV prevalence in Scotland ${ }^{7}$ and the rest of the $\mathrm{UK}^{35-38}$ had been studied regionally. To overcome the uncertainty in interpreting results from selected geographical areas and to allow comparison of regional differences, we undertook the first national HCV seroprevalence study among childbearing women in Scotland.

Unlinked anonymous testing of residual dried blood spots on neonatal metabolic screening cards has been performed for many years for HIV, ${ }^{39-41}$ and more recently for $\mathrm{HCV},{ }^{37}$ and is regarded as the most cost effective means of providing minimally biased estimates of prevalence in a large general population. ${ }^{42}$ Due to the anonymous nature of these surveys, 
Table 2 Extent and characteristics of diagnosed hepatitis $\mathrm{C}$ virus $(\mathrm{HCV})$ infection among women delivering live births in Scotland during April-September 2000

\begin{tabular}{|c|c|c|c|c|c|c|}
\hline \multirow{3}{*}{$\begin{array}{l}\text { Health board } \\
\text { area }\end{array}$} & \multirow[b]{3}{*}{ Age (y) } & \multicolumn{2}{|c|}{$\begin{array}{l}\text { Unlinked data from anonymous } \\
\text { HCV testing survey }\end{array}$} & \multicolumn{3}{|c|}{ Linked data from Scotland's databases of births and diagnosed HCV infections } \\
\hline & & \multirow{2}{*}{$\begin{array}{l}\text { No tested } \\
n_{1}\end{array}$} & \multirow{2}{*}{$\begin{array}{l}\begin{array}{l}\text { Estimated anti-HCV } \\
\text { positive* }\end{array} \\
n_{2}\left(\% \text { of } n_{1}\right)\end{array}$} & \multirow{2}{*}{$\begin{array}{l}\begin{array}{l}\text { Estimated } \mathrm{HCV} \\
\text { diagnosed before } \\
\text { pregnancy }\end{array} \\
\mathrm{n}_{3}\left(\% \text { of } \mathrm{n}_{2}\right)\end{array}$} & \multirow{2}{*}{$\begin{array}{l}\text { Estimated HCV } \\
\text { diagnosed during } \\
\text { pregnancy } \\
n_{4}\left(\% \text { of } n_{2}-n_{3}\right) \\
\end{array}$} & \multirow{2}{*}{$\begin{array}{l}\text { Estimated HCV diagnosed } \\
\text { overall (ie, before birth) } \\
n_{5}\left(\% \text { of } n_{2}\right)\end{array}$} \\
\hline & & & & & & \\
\hline \multicolumn{7}{|c|}{ Greater Glasgow } \\
\hline & $<20$ & 322 & $0(0.00 \%)$ & - & - & - \\
\hline & $20-24$ & 781 & $6(0.77 \%)$ & $1(16.7 \%)$ & $5(100.0 \%)$ & $6(100.0 \%)$ \\
\hline & $25-29$ & 995 & $18(1.81 \%)$ & $3(16.7 \%)$ & $3(20.0 \%)$ & $6(33.3 \%)$ \\
\hline & $30-34$ & 1347 & 21 (1.56\%) & $4(19.0 \%)$ & $3(17.6 \%)$ & $7(33.3 \%)$ \\
\hline & $\geqslant 35$ & 833 & $3(0.36 \%)$ & $1(33.3 \%)$ & $0(0.0 \%)$ & $1(33.3 \%)$ \\
\hline Total (includi & g unknowns) & 4364 & $48(1.10 \%)$ & $9(18.8 \%)$ & $11(28.2 \%)$ & $20(41.7 \%)$ \\
\hline \multicolumn{7}{|c|}{ Grampian } \\
\hline & $<20$ & 143 & $2(1.40 \%)$ & $0(0.0 \%)$ & $1(50.0 \%)$ & $1(50.0 \%)$ \\
\hline & $20-24$ & 378 & $7(1.85 \%)$ & $2(28.6 \%)$ & $3(60.0 \%)$ & 5 (71.4\%) \\
\hline & $25-29$ & 716 & $3(0.42 \%)$ & $2(66.7 \%)$ & $1(100.0 \%)$ & $3(100.0 \%)$ \\
\hline & $30-34$ & 823 & $4(0.49 \%)$ & $1(25.0 \%)$ & $0(0.0 \%)$ & $1(25.0 \%)$ \\
\hline & $\geqslant 35$ & 445 & $0(0.00 \%)$ & - & - & - \\
\hline \multirow{2}{*}{\multicolumn{7}{|c|}{ Rest of Scotland }} \\
\hline & & & & & & \\
\hline & $<20$ & 1266 & $1(0.08 \%)$ & $1(100.0 \%)$ & - & $1(100.0 \%)$ \\
\hline & $20-24$ & 3016 & $9(0.30 \%)$ & $3(33.3 \%)$ & $4(66.7 \%)$ & $7(77.8 \%)$ \\
\hline & $25-29$ & 4879 & $21(0.43 \%)$ & $4(19.0 \%)$ & $4(23.5 \%)$ & $8(38.1 \%)$ \\
\hline & $30-34$ & 5758 & $8(0.14 \%)$ & $5(62.5 \%)$ & $0(0.0 \%)$ & $5(62.5 \%)$ \\
\hline & $\geqslant 35$ & 3371 & $7(0.21 \%)$ & $0(0.0 \%)$ & $0(0.0 \%)$ & $0(0.0 \%)$ \\
\hline \multirow{6}{*}{ All Scotland } & g unknowns) & 18741 & $48(0.26 \%)$ & $13(27.1 \%)$ & $8(22.9 \%)$ & $21(43.8 \%)$ \\
\hline & $<20$ & 1731 & $3(0.17 \%)$ & $1(33.3 \%)$ & $1(50.0 \%)$ & $2(66.7 \%)$ \\
\hline & $20-24$ & 4178 & $22(0.53 \%)$ & $6(27.3 \%)$ & $12(75.0 \%)$ & $18(81.8 \%)$ \\
\hline & $25-29$ & 6591 & $42(0.64 \%)$ & 9 (21.4\%) & $8(24.2 \%)$ & $17(40.5 \%)$ \\
\hline & $30-34$ & 7933 & $33(0.42 \%)$ & $10(30.3 \%)$ & $3(13.0 \%)$ & $13(39.4 \%)$ \\
\hline & $\geqslant 35$ & 4652 & $10(0.22 \%)$ & $1(10.0 \%)$ & $0(0.0 \%)$ & 1 (10.0\%) \\
\hline Total (includi & g unknowns) & 25641 & $112(0.44 \%)$ & $27(24.1 \%)$ & $24(28.2 \%)$ & $51(45.5 \%)$ \\
\hline
\end{tabular}

participation bias is generally avoided; the proportion of women $(0.03 \%)$ who refused testing was too small to influence overall prevalence rates. Women who had perinatal deaths $(<1 \%$ of all births $)$ however could not be taken into account because stored specimens from these cases were unavailable for retrospective testing. Our data reflect women giving birth but may not necessarily represent all females of childbearing age; the ratio of HCV prevalence in childbearing women to that in all women is influenced by HCV related risk factors that are different for childbearers and non-childbearers and also by differences in fertility between HCV infected and uninfected women. ${ }^{42}$ Nevertheless, repeat prevalence surveys at, for example, three yearly intervals will allow the incidence of HCV, and thus the effectiveness of interventions to prevent it, to be gauged over time.

The overall prevalence of maternal anti-HCV infection detected was low $(0.29-0.4 \%)$, comparable with a previously modelled central estimate for Scotland $(0.29 \%),{ }^{37}$ higher than that modelled for England/Wales (0.15\%), ${ }^{37}$ although lower than regional estimates from the rest of Western Europe $(1-2 \%),{ }^{16}$ the USA $(2-4 \%),{ }^{43-45}$ and Australia (1.1\%). ${ }^{46}$ While a quarter (33/121) of the dried blood spot samples reactive on repeat ELISA tests were unconfirmed on RIBA, there was supporting evidence to indicate that at least $40 \%$ of these were true positives. ${ }^{47}$ Extrapolating from the observed 0.29 0.4\% HCV seroprevalence in 30259 samples to all 53076 births in Scotland during 2000, and assuming that $80 \%$ of infected mothers were viraemic ${ }^{48}$ there were an estimated $((0.0029-0.004) \times 0.8 \times 53076) 123-170$ births to HCV carrier mothers; assuming a mother to child transmission rate of $6.2 \%,{ }^{9} 8$ to $11 \mathrm{HCV}$ infected infants were born.

Interpretation of the Scottish data is limited because of the lack of behavioural information collected through the unlinked anonymous programme. Nevertheless, the distribution of HCV infection among Scottish childbearing women was consistent with parameters of injecting drug use epidemiology. Firstly, a significantly higher prevalence of maternal infection was found among women residing in areas recognised as the most highly deprived in the UK..$^{29}$ Low socioeconomic status among pregnant women-specifically unemployment, unmarried condition, and a history of previous abortion-has previously been correlated with higher HCV seroprevalence. ${ }^{49}$ Secondly, marked geographical variation in maternal prevalence was observed; areas with the highest rates-Greater Glasgow (0.83-0.96\%) and Grampian (0.38-0.62\%)-were the same as those with the greatest prevalences of HCV infected (current) injecting drug users $(0.86 \%$ and $0.55 \%$ per population aged $15-54$ years in Greater Glasgow and Grampian, respectively, compared with lower rates of $0.06-0.31 \%$ elsewhere in Scotland ${ }^{20}$ ). Also, HCV seroprevalences peaks among childbearing women aged 2534 years in Greater Glasgow and 15-24 years in Grampian, a difference which reflects the respective older and younger drug user populations in these areas. ${ }^{20}$ Record linkage of Scotland's databases of births and diagnosed HCV infections further established injecting drug use as the predominant risk factor for HCV acquisition among childbearing women in 95\% of diagnosed cases with known risk factors.

Universal HCV screening in pregnancy is considered to be unjustified given the absence of an intervention to prevent mother to child transmission. ${ }^{14-1735}$ Nevertheless, it is also recognised that antenatal HCV testing provides an opportunity to identify asymptomatic women with chronic disease who, following pregnancy, may benefit from antiviral therapy at a time when they are most receptive to medical intervention. ${ }^{12}$ The results of this study demonstrate however 
that the current de facto selective antenatal screening policy, to offer a test only to women with a history of injecting drug use or other risk factors for infection, ${ }^{18} 19$ failed to identify $72 \%(28 \%$ and $83 \%$ among $<25$ and $\geqslant 25$ year olds, respectively) of previously undetected HCV infections; while the reasons for such non-identification of cases would likely be a combination of failure to identify those at high risk, failure to offer an HCV test, and non-acceptance of a test, such information was unavailable. These findings are consistent with those generated by local studies in the $\mathrm{UK}^{76}$ and indicate that the universal offer and recommendation of a HCV test would need to be introduced if an efficient intervention to prevent mother to child transmission became available.

Another finding of value is the proportion of the infected population who had been diagnosed before pregnancy (24\%; 27/112). While it is possible that some of the 85 undetected infections could have occurred during pregnancy-thus leading to an underestimate of the proportion diagnosedsuch detection rate data can be used to estimate indirectly the number of prevalent (diagnosed and undiagnosed) HCV infections in Scotland. ${ }^{50}$ Robust estimates of the prevalent number of HCV infections are required to estimate the total burden of current and future disease and thus facilitate the planning of future HCV related healthcare services. ${ }^{3}$

\section{ACKNOWLEDGEMENTS}

We thank the many midwives, health visitors, and others involved in sample collection, and obstetricians, paediatricians, general practitioners, and administrative and clerical staff for their help. We thank the Information and Statistics Division Record Linkage Team in Edinburgh for electronically linking SCIEH's HCV diagnosis database with Scotland's maternity inpatient and day case register.

This study was supported by the Scottish Executive Department of Health.

\section{Authors' affiliations}

S J Hutchinson, Scottish Centre for Infection and Environmental Health, Glasgow, UK, and Public Health and Health Policy Section, University of Glasgow, Glasgow, UK

D J Goldberg, LE Shaw, Scottish Centre for Infection and Environmental Health, Glasgow, UK

S O Cameron, K Wilson, L MacDonald, Regional Virus Laboratory,

Gartnavel Hospital, Glasgow, UK

M King, A Brown, J MacKenzie, Scottish National Neonatal Screening Laboratory, Glasgow, UK

\section{REFERENCES}

1 WHO Consultation group. Global surveillance and control of hepatitis C. $J$ Viral Hepat 1999;6:35-47.

2 Di Bisceglie AM. Hepatitis C. Lancet 1998:351:351-5.

3 Goldberg D, Taylor A, Hutchinson S, et al. Hepatitis C infection among injecting drug users in Scotland: stemming the flow. Scott Med J 2000;45:131-2

4 Wodak A Crofts N. Once more unto the breach: controlling hepatitis $C$ in injecting drug users. Addiction 1996:91:181-4.

5 Donahue JG, Muñoz A, Ness PM, et al. The declining risk of post-transfusion hepatitis C virus infection. N Engl J Med 1992;327:369-73

6 Wejstål R. Sexual transmission of hepatitis $C$ virus. J Hepatol 1999:31(suppl 1):92-5.

7 Goldberg D, Mclntyre PG, Smith R, et al. Hepatitis $C$ virus among high and low risk pregnant women in Dundee: unlinked anonymous testing. $\mathrm{Br} J$ Obstet Gynaecol 2001;108:365-70.

8 Scott GR. The sexual transmission of hepatitis C virus. Int J STD AIDS 1995:6:1-3.

9 Dore GJ, Kaldor JM, McCaughan GW. Systematic review of role of polymerase chain reaction in defining infectiousness among people infected with hepatitis C virus. BMJ 1997;315:333-7.

10 Thomas SL, Newell M-L, Peckham CS, et al. A review of hepatitis C (HCV) vertical transmission: risks of transmission to infants born to mothers with and without HCV viraemia or human immunodeficiency virus. Int J Epidemiol 1998;27:108-17

11 Gibb DM, Goodall RL, Dunn DT, et al. Mother-to-child transmission of hepatitis $C$ virus: evidence for preventable peripartum transmission. Lancet 2000;356:904-7.

12 Hadžić N. Hepatitis C in pregnancy. Arch Dis Child Fetal Neonatal Ed 2001;84:F201-4.

13 Jones M. Hepatitis C infection in children. N Engl J Med 1999;341:912-3.
14 Zein NN. Vertical transmission of hepatitis C: to screen or not to screen. J Pediatr 1997; 130:859-61.

15 American Academy of Pediatrics (Committee on Infectious Diseases). Hepatitis C virus infection. Pediatrics 1998;101:481-5.

16 European Paediatric HCV Network, Pembrey L, Newell M-L, Tovo P-A Antenatal hepatitis $C$ virus screening and management of infected women and their children: policies in Europe. Eur J Pediatr 1999;158:842-6.

17 Hay JE. Viral Hepatitis in Pregnancy. Viral Hepat Rev 2000;6:205-15.

18 Scottish Needs Assessment Programme. Hepatitis C. Glasgow: Office for Public Health in Scotland, 2000.

19 Department of Health. Hepatitis C strategy for England. London: Department of Health, 2002.

20 Hay G, McKeganey N, Hutchinson SJ, on behalf of the project team. Estimating the national and local prevalence of problem drug misuse in Scotland. Edinburgh: ISD, 2001.

21 Registrar General for Scotland. Annual report of the registrar general of births, deaths and marriages for Scotland, 2000. Edinburgh: RGOS, 2001

22 General Register Office for Scotland. Scotland's census 2001. The Registrar General's 2001 census report to the Scottish Parliament. Edinburgh: GROS, 2003.

23 Data Analysis Products Division. S-PLUS 2000 guide to statistics, Vol 1. Seattle: MathSoft, 1997.

24 StatXact-5 for Windows. Massachusetts: Cytel Software Corporation, 2001.

25 Tappin DM, Girdwood RWA, Follett EAC, et al. Prevalence of maternal HIV infection in Scotland based on unlinked anonymous testing of newborn babies. Lancet 1991;337:1565-7.

26 Parker SP Cubitt WD, Ades AE. A method for the detection and confirmation of antibodies to hepatitis $\mathrm{C}$ virus in dried blood spots. J Virol Methods 1997;68:199-205.

27 Ades AE, Parker S, Walker J, et al. HCV prevalence in pregnant women in the UK. Epidemiol Infect 2000;125:399-405.

28 McCarron B, Fox R, Wilson $\mathrm{K}$, et al. Hepatitis $\mathrm{C}$ antibody detection in dried blood spots. J Viral Hepat 1999;6:453-6.

29 Carstairs V, Morris R. Deprivation and health in Scotland. Aberdeen: Aberdeen University Press, 1991.

30 Mcloone P. Carstairs scores for Scottish postcode sectors from the 1991 census. Glasgow: Public Health Research Unit, University of Glasgow, 1994.

31 Scottish Centre for Infection and Environmental Health. Surveillance of known Hepatitis C antibody positive cases in Scotland: results to 31 December 2001. SCIEH Weekly Report 2002;36:142-7.

32 Information and Statistics Division. Scottish health statistics 2000. Edinburgh: ISD, 2001.

33 Kendrick S, Clarke J. The Scottish Record Linkage System. Health Bull (Edinb) 1993;51:72-9

34 Alter MJ, Kruszon-Moran D, Nainan OV, et al. The prevalence of hepatitis C virus infection in the United States, 1988 through 1994. N Engl J Med 1999;341:556-62.

35 Boxall E, Skidmore S, Evans $C$, et al. The prevalence of hepatitis $B$ and $C$ in an antenatal population of various ethnic origins. Epidemiol Infect 1994:113:523-8.

36 Ward C, Tudor-Williams G, Cotzias T, et al. Prevalence of hepatitis C among pregnant women attending an inner London obstetric department: uptake and acceptability of named antenatal testing. Gut 2000;47:277-80.

37 Ades AE, Parker S, Walker J, et al. HCV prevalence in pregnant women in the UK. Epidemiol Infect 2000;125:399-405.

38 Balogun MA, Ramsay ME, Parry JV, et al. The prevalence and genetic diversity of hepatitis $C$ infection in antenatal clinic attenders in two regions of England. Epidemiol Infect 2000;125:705-12.

39 Gibb DM, Faulknall W, Noakes L, et al. Coverage of routine neonatal metabolic screening in children born to women known to be infected with HIV-1. Commun Dis Rep CDR Rev 1995;5:123-4.

40 Tappin DM, Cockburn F. Ethics and ethics committees: HIV serosurveillance in Scotland. J Med Ethics 1992;18:43-6

41 Walter EB, Elliott AJ, Regan AN, et al. Maternal acceptance of voluntary human immunodeficiency virus antibody testing during the newborn period with the Guthrie card. Pediatr Infect Dis J 1995;14:376-81.

42 Boisson E, Nicoll A, Zaba B, et al. Interpreting HIV seroprevalence data from pregnant women. J AIDS Human Retrovirol 1996;13:434-9.

43 Bohman VR, Stettler RW, Little BB, et al. Seroprevalence and risk factors for hepatitis $C$ virus antibody in pregnant women. Obstet Gynecol 1992;80:609-13.

44 Leikin EL, Reinus JF, Schmell E, et al. Epidemiologic predictors of hepatitis C virus infection in pregnant women. Obstet Gynecol 1994;84:529-34.

45 Silverman NS, Snyder M, Hodinka RL, et al. Detection of hepatitis C virus antibodies and specific hepatitis $C$ virus ribonucleic acid sequences in corc bloods from a heterogeneous prenatal population. Am J Obstet Gynecol 1995; 173:1396-400.

46 Garner JJ, Gaughwin M, Dodding J, et al. Prevalence of hepatitis C infection in pregnant women in South Australia. Med J Aust 1997;166:470-2.

47 Dow BC, Buchanan I, Munro H, et al. Relevance of RIBA-3 supplementary tes to HCV PCR positivity and genotypes for HCV confirmation of blood donors. J Med Virol 1996:49:132-6.

48 Alter HJ, Seeff LB. Recovery, persistence, and sequelae in hepatitis C virus infection: a perspective on long-term outcome. Semin Liver Dis 2000;20:17-35.

49 Baldo V, Floreani A, Menegon T, et al. Hepatitis C virus, hepatitis B virus and human immunodeficiency virus infection in pregnant women in North-East Italy: a seroepidemiological study. Eur J Epidemiol 2000;16:87-91.

50 Bird SM, Goldberg DJ, Hutchinson SJ. Projecting severe sequelae of injectionrelated hepatitis $C$ virus epidemic in the UK. J Epidemiol Biostat $2001 ; 6: 267-77$. 